\title{
Integrated Analysis for Identifying Radix Astragali and Its Adulterants Based on DNA Barcoding
}

\author{
Sihao Zheng, ${ }^{1}$ Dewang Liu, ${ }^{2}$ Weiguang Ren, ${ }^{1}$ Juan Fu, ${ }^{1}$ Linfang Huang, ${ }^{1}$ and Shilin Chen ${ }^{3}$ \\ ${ }^{1}$ Institute of Medicinal Plant Development, Chinese Academy of Medical Sciences, Peking Union Medical College, Beijing 100193, China \\ ${ }^{2}$ School of Pharmacy, Inner Mongolia Medical University, Inner Mongolia 010080, China \\ ${ }^{3}$ Institute of Chinese Materia Medica, China Academy of Chinese Medical Sciences, Beijing 100700, China
}

Correspondence should be addressed to Linfang Huang; lfhuang@implad.ac.cn

Received 15 June 2014; Accepted 22 July 2014; Published 27 August 2014

Academic Editor: Robert Henry

Copyright (C) 2014 Sihao Zheng et al. This is an open access article distributed under the Creative Commons Attribution License, which permits unrestricted use, distribution, and reproduction in any medium, provided the original work is properly cited.

\begin{abstract}
Radix Astragali is a popular herb used in traditional Chinese medicine for its proimmune and antidiabetic properties. However, methods are needed to help distinguish Radix Astragali from its varied adulterants. DNA barcoding is a widely applicable molecular method used to identify medicinal plants. Yet, its use has been hampered by genetic distance, base variation, and limitations of the bio-NJ tree. Herein, we report the validation of an integrated analysis method for plant species identification using DNA barcoding that focuses on genetic distance, identification efficiency, inter- and intraspecific variation, and barcoding gap. We collected 478 sequences from six candidate DNA barcodes (ITS2, ITS, $p s b \mathrm{~A}-t r n \mathrm{H}, r b c \mathrm{~L}, m a t \mathrm{~K}$, and COI) from 29 species of Radix Astragali and adulterants. The internal transcribed spacer (ITS) sequence was demonstrated as the optimal barcode for identifying Radix Astragali and its adulterants. This new analysis method is helpful in identifying Radix Astragali and expedites the utilization and data mining of DNA barcoding.
\end{abstract}

\section{Introduction}

Radix Astragali (Huang Qi), a commonly used Chinese medicinal material, is mainly sourced from the plants of Astragalus membranaceus and Astragalus mongholicus according to Chinese Pharmacopoeia (2010 edition). Radix Astragali is widely used for its antiperspirant, antidiuretic, and antidiabetic properties and as a tonic drug [1-3]. It possesses various beneficial compounds, including astragalosides, isoflavonoids, isoflavones, isoflavan, and pterocarpan glycosides [4-6].

Due to the high market demand for Radix Astragali, a diverse group of adulterants with similar-morphological characteristics from genuses, such as Astragalus, Hedysarum, and Malva are often used in its stead [7]. The traditional methods used to identify Radix Astragali for use as a medicinal material, such as morphological and microscopic identification [8], thin-layer chromatography and Ultraviolet spectroscopy [9], Fourier Transform infrared spectroscopy (FTIR) [10], and high performance liquid chromatography (HPLC) [11], all, require specialized equipment and training.
Several PCR-based molecular methods have been developed, providing an alternative means of identification. Multiplex PCR methods of DNA fragment analysis, such as randomly amplified polymorphic DNA (RAPD) [12] or amplified fragment length polymorphism (AFLP) [13], are unstable for the results to identify. DNA barcoding is a widely used molecular marker technology, first proposed by Hebert et al. [14, 15]. It uses a standardized and conserved, but diverse, DNA sequence to identify species and uncover biological diversity $[16,17]$. In previous studies, various coding sequences for identifying Radix Astragali and its adulterants have been used, such as the 5S-rRNA spacer domain [18], $3^{\prime}$ untranslated region ( $3^{\prime}$ UTR) [19], ITS (internal transcribed spacer region) and 18S rRNA [3, 20, 21], ITS2 [22], ITS1 [6], matK (maturase $\mathrm{K}$ ) and $r b c \mathrm{~L}$ (ribulose 1, 5-bisphosphate carboxylase) of chloroplast genome, and coxI (cytochrome c oxidase 1) of the mitochondrial genome [23]. However, sequence analysis was mainly focused on genetic distance, variable sites, amplified polymorphisms, and the use of a modified neighbor-joining (NJ) algorithm, Bio-NJ tree, which were basic analyses limited to particular species. A more effective 
TABLE 1: Taxon sampling information of astragalus and its adulterants.

\begin{tabular}{|c|c|c|c|}
\hline Experiment number & species & \multicolumn{2}{|c|}{ Sampling spot } \\
\hline S1-S5 & Astragalus membranaceus & Shaanxi & China \\
\hline SD1-SD9 & Astragalus membranaceus & Shaanxi & China \\
\hline GS1-GS6 & Astragalus mongholicus & Gansu & China \\
\hline NM1-NM10 & Astragalus mongholicus & Neimeng & China \\
\hline SX1-SX10 & Astragalus mongholicus & Shanxi & China \\
\hline HHQ1-HHQ7 & Astragalus chinensis & Beijing & China \\
\hline CY1-CY6 & Astragalus scaberrimus & Beijing & China \\
\hline JK1-JK3 & Malva pusilla & Shaanxi & China \\
\hline MX & Medicago sativa & Shaanxi & China \\
\hline HH1-HH7 & Melilotus officinalis & Shaanxi & China \\
\hline HQ1-HQ12 & Hedysarum polybotrys & Gansu & China \\
\hline $\mathrm{XJ}$ & Astragalus adsurgens & Beijing & China \\
\hline
\end{tabular}

method of molecular identification is necessary. The current study evaluates the identification reliability and efficiency of DNA barcoding for the identification of Radix Astragali using six indicators of genetic distance, identification efficiency, intra- and interspecific variation, gap rate, and barcoding gap. Six barcodes were selected for identification because they are commonly used in plant, especially in medicinal plant. We collected Radix Astragaliand several of its adulterants reported in previous research and downloaded the genetic sequences from the GenBank database. A total of 29 species (including 19 species of Astragalus) and 478 sequences from six barcodes were used to validate the new method for identifying Radix Astragali and adulterants and to accelerate the data utilization of DNA barcoding.

\section{Materials and Methods}

2.1. Materials Information. A total of 77 specimens were collected from two origins of Radix Astragali, along with seven adulterants. Radix Astragali specimens were collected from Inner Mongolia, Shaan xi, and Gan su provinces in the People's Republic of China, which are the main producing areas. The collection information is shown in Table 1. All corresponding voucher specimens were deposited in the Herbarium of the Institute of Medicinal Plant Development at the Chinese Academy of Medical Sciences in Beijing, China. The GenBank accession number of the ITS2 in this experiment was orderly KJ999296-KJ999344, the accession number of ITS sequences was orderly KJ999345-KJ999416, and the accession number of psbA-trn $\mathrm{H}$ was orderly KJ999256KJ999295. The sequences added in the subsequent analysis, including ITS, ITS2, $p s b \mathrm{~A}-\operatorname{trn} \mathrm{H}$, mat $\mathrm{K}$, and $r b c \mathrm{~L}$, were downloaded from the GenBank database.

\subsection{DNA Extraction, PCR Amplification, and Sequencing.} The material specimens were naturally dried and $30 \mathrm{mg}$ of dried plant material was used for the DNA extraction. Samples were rubbed for two minutes at a frequency of 30 r/s in a FastPrep bead mill (Retsch MM400, Germany), and total genomic DNA was isolated from the crushed material according to the manufacturer's instructions (Plant
Genomic DNA Kit, Tiangen Biotech Co., China). We made the following modifications to the protocol: chloroform was diluted with isoamyl alcohol (24:1 in the same volume) and buffer solution GP2 with isopropanol (same volume). The powder, $700 \mu \mathrm{L}$ of $65^{\circ} \mathrm{C} \mathrm{GP} 1$, and $1 \mu \mathrm{L} \beta$-mercaptoethanol were mixed for 10-20 s before being incubated for 60 minutes at $65^{\circ} \mathrm{C}$. Then, $700 \mu \mathrm{L}$ of the chloroform:isoamyl alcohol mixture was added and the solution was centrifuged for 5 minutes at $12000 \mathrm{rpm}(\sim 13400 \times \mathrm{g})$. Supernatant was removed and placed into a new tube before adding $700 \mu \mathrm{L}$ isopropanol and blending for 15-20 minutes. The mixture was centrifuged in CB3 spin columns for $40 \mathrm{~s}$ at $12000 \mathrm{rpm}$. The filtrate was discarded and $500 \mu \mathrm{L}$ GD (adding quantitative anhydrous ethanol before use) was added before centrifuging at $12000 \mathrm{rpm}$ for $40 \mathrm{~s}$. The filtrate was discarded and $700 \mu \mathrm{L}$ PW (adding quantitative anhydrous ethanol before use) was used to wash the membrane before centrifuging for $40 \mathrm{~s}$ at $12000 \mathrm{rpm}$. This step was repeated with $500 \mu \mathrm{L}$ PW, followed by a final centrifuge for 2 minutes at $12000 \mathrm{rpm}$ to remove residual wash buffer. The spin column was dried at room temperature for 3-5 minutes and then centrifuged for 2 minutes at $12000 \mathrm{rpm}$ to obtain the total DNA.

General PCR reaction conditions and universal DNA barcode primers were used for the ITS, ITS2, and $p s b \mathrm{~A}-\operatorname{tr} n \mathrm{H}$ barcodes, as presented in Table 2 [24-26]. PCR amplification was performed on $25-\mu \mathrm{L}$ reaction mixtures containing $2 \mu \mathrm{L}$ DNA template (20-100 ng), $8.5 \mu \mathrm{L}$ ddH2O, $12.5 \mu \mathrm{L} 2 \times$ Taq PCR Master Mix (Beijing TransGen Biotech Co., China), and $1 / 1-\mu \mathrm{L}$ forward/reverse $(\mathrm{F} / \mathrm{R})$ primers $(2.5 \mu \mathrm{M})$. The reaction mixtures were amplified in a 9700 GeneAmp PCR system (Applied Biosystems, USA). Amplicons were visualized by electrophoresis on $1 \%$ agarose gels. Purified PCR products were sequenced in both directions using the ABI 3730XL sequencer (Applied Biosystems, USA).

2.3. Sequence Assembly, Alignment, and Analysis. Sequencing peak diagrams were obtained and proofread, and then contigs were assembled using a CodonCode Aligner 5.0.1 (CodonCode Co., USA). Complete ITS2 sequences were obtained using the HMMer annotation method, based on the Hidden Markov model (HMM) [27]. All of the sequences were 
TABLE 2: Primers and PCR reaction conditions.

\begin{tabular}{|c|c|c|}
\hline Primer name & Primer sequences $\left(5^{\prime}-3^{\prime}\right)$ & PCR reaction condition \\
\hline \multicolumn{3}{|l|}{ ITS2 } \\
\hline $2 \mathrm{~F}$ & ATGCGATACTTGGTGTGAAT & $94^{\circ} \mathrm{C} 5 \mathrm{~min}$; \\
\hline $3 \mathrm{R}$ & GACGCTTCTCCAGACTACAAT & $\begin{array}{l}94^{\circ} \mathrm{C} 30 \mathrm{~s}, 56^{\circ} \mathrm{C} 30 \mathrm{~s} \\
72^{\circ} \mathrm{C} 45 \mathrm{~s}, 40 \text { cycles; } \\
72^{\circ} \mathrm{C} 10 \mathrm{~min}\end{array}$ \\
\hline \multicolumn{3}{|l|}{ ITS } \\
\hline $4 \mathrm{R}$ & TCCTCCGCTTATTGATATGC & $94^{\circ} \mathrm{C} 5 \mathrm{~min} ;$ \\
\hline $5 \mathrm{~F}$ & GGAAGTAAAAGTCGTAACAAGG & $\begin{array}{c}94^{\circ} \mathrm{C} 1 \mathrm{~min}, 50^{\circ} \mathrm{C} 1 \mathrm{~min} \\
72^{\circ} \mathrm{C} 1.5 \mathrm{~min}+3 \mathrm{~s} / \text { cycle, } 30 \text { cycles; } \\
72^{\circ} \mathrm{C} 7 \mathrm{~min} ;\end{array}$ \\
\hline \multicolumn{3}{|l|}{$p s b \mathrm{~A}$} \\
\hline fwdPA & GTTATGCATGAACGTAATGCTC & $94^{\circ} \mathrm{C} 4 \mathrm{~min}$ \\
\hline \multicolumn{3}{|l|}{$\operatorname{trn} \mathrm{H}$} \\
\hline rev TH & CGCGCATGGTGGATTCACAATCC & $\begin{array}{l}94^{\circ} \mathrm{C} 30 \mathrm{~s}, 55^{\circ} \mathrm{C} 1 \mathrm{~min} \\
72^{\circ} \mathrm{C} 1 \mathrm{~min}, 35 \text { cycles; } \\
72^{\circ} \mathrm{C} 10 \mathrm{~min} ;\end{array}$ \\
\hline
\end{tabular}

aligned using ClustalW, in combination with 317 sequences from six commonly used barcodes (ITS2, ITS, psbA-trnH, mat $\mathrm{K}, r b c \mathrm{~L}$, and $\mathrm{COI})$, which were downloaded from the GenBank database (Table 3). Sequence genetic distance and GC content were calculated using the maximum composite likelihood model. Maximum likelihood (ML) trees were constructed based on the Tamura-Nei model, and bootstrap tests were conducted using 1000 repeats to assess the confidence of the phylogenetic relationships by MEGA 6.0 software [28]. The barcoding gap, defined as the spacer region between intra- and interspecific genetic variations, and identification efficiency, based on BLAST1 and K2P nearest distance, were performed by the Perl language algorithm (Putty) $[25,29,30]$.

\section{Results}

3.1. Sequence Information and Identification Efficiency. A total of 478 sequences for six barcodes were analyzed, from which 161 sequences were obtained from Astragalus Radix and its adulterants. Sequence information and identification success rates are listed in Table 4 . The average GC content of six barcodes was discrepant, and ITS and ITS2 regions from nuclear ribosomal DNA performed higher than other barcodes (52.97\% versus 50.80\%). Among the six barcodes, ITS2 provided the largest average genetic distance (1.0792), and $\mathrm{rbcL}$ was the smallest (0.0349). All of the six barcodes obtained a zero value for the minimum genetic distance. In terms of identification efficiency, the nearest distance method was superior to the BLAST1 method for all of the six barcodes. Moreover, ITS and the $p s b \mathrm{~A}-t r n \mathrm{H}$ and $m a t \mathrm{~K}$ regions provided a higher rate of success than the other three barcodes using the BLAST1 method. However, matK, ITS, and $p s b \mathrm{~A}-\operatorname{trn} \mathrm{H}$ performed better than the other three barcodes, based on the nearest distance method. ITS and $p s b \mathrm{~A}-\operatorname{tr} n \mathrm{H}$ obtained higher genetic distances, so the mat K, ITS, and $p s b \mathrm{~A}-t r n \mathrm{H}$ barcodes were the preferable methods for identifying Radix Astragali and its adulterants based on superior sequencing efficiency and identification efficiency.

3.2. Intra- and Interspecific Variation Analysis Using Six Parameters. Six parameters to analyze intraspecific variation and interspecific divergence were employed to assess the utility of six DNA barcodes (Table 5). We expected the "minimum interspecific distance" would be higher than the "coalescent depth" (maximum intraspecific distance). Therefore, we first utilized the "gap rate" to indicate the distinctness, calculated by the formula: (minimum interspecific distancemaximum intraspecific distance)/minimum interspecific distance. Results show that the ITS2, COI, matK, and $r b c \mathrm{~L}$ regions outperformed the ITS and $p s b \mathrm{~A}-\operatorname{trn} \mathrm{H}$ regions for gap rates. However, when we compared all of the average interand intraspecific distances, the ITS2, $r b c \mathrm{~L}, m a t \mathrm{~K}$, and $p s b \mathrm{~A}-$ trn $\mathrm{H}$ regions performed better than the ITS and COI regions. Therefore, in terms of intra- and interspecific variation, ITS2, $m a t \mathrm{~K}$, and $r b c \mathrm{~L}$ are the preferable options for identifying Radix Astragali and its adulterants.

3.3. Barcoding Gap Analysis. Analysis of the DNA barcoding gap presents the divergence of inter- and intraspecies and indicates separate, nonoverlapping distribution between specimens in an ideal situation [25]. In our study (Figure 1), the $r b c \mathrm{~L}$, COI, ITS, and matK regions possessed less relative distribution of inter- and intraspecific variation than $p s b \mathrm{~A}-$ $\operatorname{trn} \mathrm{H}$ and ITS2, although there were no nonoverlapping regions for the six barcodes. Hence, the $r b c \mathrm{~L}$, COI, ITS, and mat $\mathrm{K}$ regions are more successful at identifying Radix Astragali and its adulterants, from the standpoint of barcoding gap analysis.

3.4. ML Tree Analysis. Maximum likelihood (ML) is a general statistical criterion in widespread use for the inference of molecular phylogenies [31]. An ML tree visually revealed the relationship between species. As the results show (Figure 2), 
TABLE 3: Sequences from GenBank for identifying Astragalus and its adulterants.

\begin{tabular}{|c|c|c|c|}
\hline Region & Family & Species & Accession number \\
\hline \multirow{13}{*}{ ITS2 } & Fabaceae & Melilotus officinalis & U50765, Z97687 \\
\hline & Fabaceae & Astragalus adsurgens & L10757, GU217639, GU217640, GU217641 \\
\hline & Fabaceae & Astragalus chinensis & GQ434365, GQ434366 \\
\hline & Fabaceae & Hedysarum polybotrys & GQ434367 \\
\hline & Fabaceae & Astragalus mongholicus & GQ434368, GU217643 \\
\hline & Fabaceae & Astragalus mongholicus var. dahuricus & GU217635 \\
\hline & Fabaceae & Astragalus membranaceus & GU217642, JF421475 \\
\hline & Fabaceae & Caragana sinica & GU217654 \\
\hline & Fabaceae & Medicago sativa & GU217662, Z99236, AF028417, JN617208 \\
\hline & Fabaceae & Medicago sativa subsp. caerulea & AF028418 \\
\hline & Fabaceae & Medicago sativa subsp. glomerata & AF028419 \\
\hline & Fabaceae & Medicago falcata & AF028420 \\
\hline & Malvaceae & Alcea rosea & AF303023 \\
\hline \multirow{39}{*}{ ITS } & \multirow{7}{*}{ Fabaceae } & \multirow{7}{*}{ Astragalus membranaceus } & AF359749, EF685968, EU852042, FJ572044, GU289659 \\
\hline & & & GU289660, GU289661, GU289662, GU289663, GU289664 \\
\hline & & & HM142272, HM142273, HM142274, HM142275, HM142276 \\
\hline & & & HM142277, HM142278, HM142279, HM142280, HM142281 \\
\hline & & & HQ891827, JX017320, JX017321, JX017322, JX017323 \\
\hline & & & JX017324, JX017325, JX017326, JX017327, JX017328 \\
\hline & & & JX017329, JX017330, JX017331, JX017332, AF121675 \\
\hline & \multirow{4}{*}{ Fabaceae } & \multirow{4}{*}{ Astragalus mongholicus } & AF359750, EF685969, HM142282, HM142283, HM142284 \\
\hline & & & HM142285, HM142286, HM142287, HM142288, HM142289 \\
\hline & & & HM142290, JF736665, JF736666, JF736667, JF736668 \\
\hline & & & JF736669, AB787166 \\
\hline & Fabaceae & Astragalus propinquus & AF359751 \\
\hline & Fabaceae & Astragalus lepsensis & AF359752 \\
\hline & Fabaceae & Astragalus aksuensis & AF359753, AB231091 \\
\hline & Fabaceae & Astragalus hoantchy & AF359754, AF521952 \\
\hline & Fabaceae & Astragalus hoantchy subsp. dshimensis & AF359755 \\
\hline & Fabaceae & Astragalus lehmannianus & AF359756 \\
\hline & Fabaceae & Astragalus sieversianus & AF359757 \\
\hline & Fabaceae & Astragalus austrosibiricus & AF359758 \\
\hline & Fabaceae & Astragalus uliginosus & EF685970 \\
\hline & Fabaceae & Astragalus scaberrimus & AB051988 \\
\hline & Fabaceae & Astragalus chinensis & FJ980292, HM142297, AF121681 \\
\hline & Fabaceae & Astragalus borealimongolicus & $\begin{array}{l}\text { HM142291, HM142292, HM142293, HM142294, HM142295 } \\
\text { HM142296 }\end{array}$ \\
\hline & Fabaceae & Astragalus adsurgens & HM142298, HM142299, HQ199326 \\
\hline & Fabaceae & Astragalus mongholicus var. dahuricus & HM142300, KC262199 \\
\hline & Fabaceae & Astragalus zacharensis & HM142301 \\
\hline & Fabaceae & Astragalus melilotoides & HM142302 \\
\hline & Fabaceae & Astragalus scaberrimus & HM142303 \\
\hline & Fabaceae & Astragalus sieversianus & AB741299 \\
\hline & Fabaceae & Oxytropis anertii & EF685971 \\
\hline & Fabaceae & Caragana sinica & DQ914785, FJ537284, GQ338283 \\
\hline & Fabaceae & Glycyrrhiza pallidiflora & EU591998, GQ246130 \\
\hline & Fabaceae & Melilotus officinalis & AB546796, JF461307, JF461308, JF461309, DQ311985 \\
\hline & Fabaceae & Medicago sativa & $\begin{array}{l}\text { GQ488541, AF053142, AY256392, JX017335, JX017336 } \\
\text { JX017337, KF938697 }\end{array}$ \\
\hline & Fabaceae & Oxytropis caerulea & GU217599, HQ199316 \\
\hline & Fabaceae & Hedysarum vicioides & HM142304, HM142305 \\
\hline & Fabaceae & Hedysarum polybotrys & JX017333, JX017334, KF032294 \\
\hline & Malvaceae & Malva neglecta & EF419478, EF419479 \\
\hline & Malvaceae & Alcea rosea & AH010172, EF419544, EF679714, JX017319 \\
\hline
\end{tabular}


TABLE 3: Continued.

\begin{tabular}{|c|c|c|c|}
\hline Region & Family & Species & Accession number \\
\hline \multirow{12}{*}{$p s b \mathrm{~A}-t r n \mathrm{H}$} & Fabaceae & Astragalus membranaceus $f$. pallidipurpureus & GQ139474 \\
\hline & Fabaceae & Astragalus adsurgens & GU396749, GU396750, GU396751, KF011553 \\
\hline & Fabaceae & Astragalus mongholicus & GU396754, AB787167 \\
\hline & & & GQ139475, GQ139476, GQ139477, GQ139478, GQ139479 \\
\hline & Fabaceae & Astragalus membranaceus & $\begin{array}{l}\text { GQ139480, GQ139481, GQ139482, GQ139483, GU396752 } \\
\text { GU396753 }\end{array}$ \\
\hline & Fabaceae & Caragana sinica & GU396767, KJ025053 \\
\hline & Fabaceae & Oxytropis caerulea & GU396771 \\
\hline & Fabaceae & Medicago sativa & GU396781, HQ596768, HE966707 \\
\hline & Fabaceae & Glycyrrhiza pallidiflora & GU396807 \\
\hline & Fabaceae & Melilotus officinalis & HE966710 \\
\hline & Malvaceae & Malva neglecta & EF419597, EF419598, HQ596765, HQ596765 \\
\hline & Malvaceae & Alcea rosea & EF419662, EF679744 \\
\hline \multirow{20}{*}{ mat K } & Fabaceae & Astragalus membranaceus & $\begin{array}{l}\text { EF685992, HM142232, HM142233, HM142234, HM142235 } \\
\text { HM142236, HM142237, HM142238, HM142239, HM142240 } \\
\text { HM142254 }\end{array}$ \\
\hline & Fabaceae & Astragalus mongholicus & $\begin{array}{l}\text { EF685993, HM142241, HM142242, HM142243, HM142244 } \\
\text { HM142245, HM142246, HM142247, HM142255, HM142256 }\end{array}$ \\
\hline & Fabaceae & Astragalus uliginosus & EF685994, HM142262 \\
\hline & Fabaceae & Astragalus mongholicus var. dahuricus & HM049531, HM142260 \\
\hline & Fabaceae & Astragalus chinensis & HM049533, HM142263 \\
\hline & Fabaceae & Astragalus adsurgens & HM049537, HM142258, HM142259, AY920437 \\
\hline & Fabaceae & Astragalus borealimongolicus & $\begin{array}{l}\text { HM142248, HM142249, HM142250, HM142251, HM142252 } \\
\text { HM142253 }\end{array}$ \\
\hline & Fabaceae & Astragalus zacharensis & HM142261 \\
\hline & Fabaceae & Astragalus melilotoides & HM142264 \\
\hline & Fabaceae & Astragalus scaberrimus & HM142265 \\
\hline & Fabaceae & Astragalus sieversianus & AB741343 \\
\hline & Fabaceae & Medicago sativa & $\begin{array}{l}\text { AF522108, HQ593363, HM851138, AY386881, HE967439 } \\
\text { AF169289 }\end{array}$ \\
\hline & Fabaceae & Oxytropis anertii & EF685995, HM142266 \\
\hline & Fabaceae & Oxytropis caerulea & HM049544 \\
\hline & Fabaceae & Glycyrrhiza pallidiflora & EF685997, HM142269, JQ619944 \\
\hline & Fabaceae & Hedysarum vicioides & EF685996, HM142257, HM142267 \\
\hline & Fabaceae & Caragana sinica & HМ049541 \\
\hline & Fabaceae & Melilotus officinalis & HE970723 \\
\hline & Malvaceae & Malva neglecta & $\begin{array}{l}\text { EU346788, HQ593360, JN894566, JN894571, JN895781 } \\
\text { JQ412262, }\end{array}$ \\
\hline & Malvaceae & Alcea rosea & EU346805 \\
\hline \multirow{11}{*}{$r b c \mathrm{~L}$} & Fabaceae & Medicago sativa & Z70173 \\
\hline & Fabaceae & Astragalus membranaceus & $\begin{array}{l}\text { EF685978, HM142199, HM142200, HM142201, HM142202 } \\
\text { HM142203, HM142204, HM142205, HM142206, HM142207 } \\
\text { HM142221 }\end{array}$ \\
\hline & Fabaceae & Astragalus mongholicus & $\begin{array}{l}\text { EF685979, HM142208, HM142209, HM142210, HM142211 } \\
\text { HM142212, HM142213, HM142214, HM142222, HM142223 }\end{array}$ \\
\hline & Fabaceae & Astragalus uliginosus & EF685980, HM142225 \\
\hline & Fabaceae & Hedysarum vicioides & EF685982, U74246, HM142224, HM142227, \\
\hline & Fabaceae & Astragalus adsurgens & EF685984 \\
\hline & Fabaceae & Astragalus borealimongolicus & $\begin{array}{l}\text { HM142215, HM142216, HM142217, HM142218, HM142219 } \\
\text { HM142220, }\end{array}$ \\
\hline & Fabaceae & Oxytropis anertii & EF685981, HM142226 \\
\hline & Fabaceae & Glycyrrhiza pallidiflora & EF685983, AB012129, HM142228 \\
\hline & Fabaceae & Caragana sinica & FJ537233 \\
\hline & Fabaceae & Melilotus officinalis & JQ933405, JX848463 \\
\hline
\end{tabular}


TABLE 4: The information of identification efficiency for six barcodes.

\begin{tabular}{|c|c|c|c|c|c|c|}
\hline Markers & $\mathrm{COI}$ & ITS2 & ITS & matK & $r b c \mathrm{~L}$ & $p s b \mathrm{~A}-t r n \mathrm{H}$ \\
\hline Number of sequences & 39 & 72 & 185 & 65 & 43 & 74 \\
\hline Average GC content/\% & 43.29 & 50.80 & 52.97 & 31.14 & 42.88 & 21.77 \\
\hline \multicolumn{7}{|l|}{ Genetic distance } \\
\hline Min & 0.0000 & 0.0000 & 0.0000 & 0.0000 & 0.0000 & 0.0000 \\
\hline Max & 0.0086 & 7.9494 & 5.3130 & 0.2801 & 0.0349 & 2.2701 \\
\hline Average & 0.0019 & 1.0792 & 0.3508 & 0.0711 & 0.0116 & 0.5080 \\
\hline \multicolumn{7}{|l|}{ Identification efficiency $/ \%$} \\
\hline BLAST 1/\% & 10.26 & 12.50 & 30.81 & 29.23 & 23.26 & 29.73 \\
\hline Nearest distance $/ \%$ & 33.33 & 27.78 & 52.43 & 66.15 & 37.21 & 41.89 \\
\hline
\end{tabular}

TABLE 5: Analysis of interspecific divergence and intraspecific variation for six barcodes.

\begin{tabular}{lcccccc}
\hline Marker $($ Mean \pm SD) & COI & ITS2 & ITS & matK & $r b c L$ & $p s b \mathrm{~A}-t r n \mathrm{H}$ \\
\hline Theta & $2.2260 \pm 6.2961$ & $0.0030 \pm 0.0046$ & $0.0271 \pm 0.0404$ & $0.0021 \pm 0.0035$ & $0.0011 \pm 0.0020$ & $0.2415 \pm 0.4777$ \\
Coalescent depth & $0.0001 \pm 0.0004$ & $0.0040 \pm 0.0046$ & $0.1423 \pm 0.3958$ & $0.0032 \pm 0.0050$ & $0.0016 \pm 0.0030$ & $0.4109 \pm 0.5683$ \\
All intraspecific distance & $9.3280 \pm 0.0003$ & $0.0021 \pm 0.0024$ & $0.1153 \pm 0.3051$ & $0.0014 \pm 0.0022$ & $0.0002 \pm 0.0011$ & $0.3093 \pm 0.4300$ \\
Theta prime & $0.0012 \pm 0.0008$ & $0.0617 \pm 0.0302$ & $0.0603 \pm 0.0371$ & $0.0091 \pm 0.0061$ & $0.0024 \pm 0.0035$ & $0.3083 \pm 0.2887$ \\
Minimum interspecific distance & $0.0008 \pm 0.0010$ & $0.0440 \pm 0.0386$ & $0.0168 \pm 0.0196$ & $0.0066 \pm 0.0066$ & $0.0023 \pm 0.0035$ & $0.0423 \pm 0.0380$ \\
All interspecific distance & $0.0007 \pm 0.0010$ & $0.0343 \pm 0.0389$ & $0.1066 \pm 0.2833$ & $0.0071 \pm 0.0064$ & $0.0015 \pm 0.0029$ & $0.3166 \pm 0.4070$ \\
Gap rate/\% & 87.50 & 90.91 & $/$ & 51.52 & 30.43 & $/$ \\
\hline
\end{tabular}

$p s b \mathrm{~A}-t r n \mathrm{H}$ successfully differentiated Radix Astragali and its adulterants. Furthermore, it produced areas of obvious separation for Radix Astragali. The remaining five barcodes also differentiated Radix Astragali and its adulterants. Each species clustered together, separate from other species. Considering the difficult amplification and sequencing and fast and accurate identification purpose of DNA barcoding, we did not add all the sequence data of ITS2 and $p s b \mathrm{~A}-\operatorname{trn} \mathrm{H}$ to build ML tree and subsequent analysis.

\section{Discussion and Conclusions}

Radix Astragali is reported to possess 47 bioactive compounds and has many bioactive properties [32-37]. Various Radix Astragali preparations are commercially available, not only in China as a TCM component, but also in the United States, as dietary supplements [38]. However, due to increasing demand, substitutes and adulterants have flooded the market. Traditional identification methods, such as morphological and microscopic methods, are limited by the lack of explicit criteria for character selection or coding and, thus, mainly depend on subjective assessments. Although chemical methods are able to distinguish between different species, it is difficult to differentiate sibling species that possess similar chemical compositions. In addition, chemical methods are unable to provide accurate species authentication. Several types of molecular markers for characterizing genotypes are useful in identifying plant species. For example, RAPD has been used to estimate genetic diversity in plant populations based on amplification of random DNA fragments and comparisons of common polymorphisms. DNA barcoding is advocated for species identification, due to its universal applicability, simplicity, and scientific accuracy. However, the analysis methods for DNA barcodes were limited. With the development of molecular biology and bioinformatics, a more improved analytic method for DNA barcoding can be established to identify Radix Astragali and closely related species.

In this study, we validated a new analytical method for identifying Radix Astragali using DNA barcoding. Seventyseven specimens of Radix Astragali and its adulterants were collected, and the sequences of 29 species reported in the literature were downloaded from the GenBank database. Based on the 478 sequences for six barcodes (ITS2, ITS from nuclear genome; $p s b \mathrm{~A}-t r n \mathrm{H}, r b c \mathrm{~L}$, and mat $\mathrm{K}$ from chloroplast genome; COI from mitochondrial genome), genetic distance and ML Tree were calculated by MEGA 6.0 software, and identification efficiency, intra- and interspecific variation, and barcoding gap were calculated using the Perl language algorithm. Results of the six indicators assessed are shown in Table 6. ITS and psbA-trn H outperformed other barcodes in terms of identification efficiency. ITS2 performed better in terms of genetic distance, gap rate, and inter- and intraspecific variation. $R b c \mathrm{~L}$ performed better in terms of barcoding gap and inter- and intraspecific variation. Although ITS2 was part of the ITS sequence, it performed poorly in identification efficiency. Therefore, we suggest that the ITS sequence is the optimal barcode, and that the $p s b \mathrm{~A}-t r n \mathrm{H}$ region is a complementary barcode for identifying Radix Astragali and its adulterants.

In conclusion, we describe a new analytical method for the use of DNA barcoding in the identification of Radix 


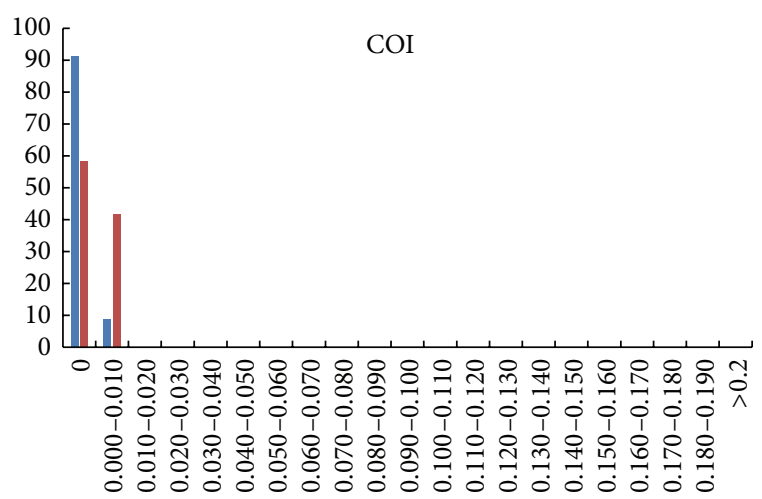

- Intraspecies

- Interspecies

(a)

ITS

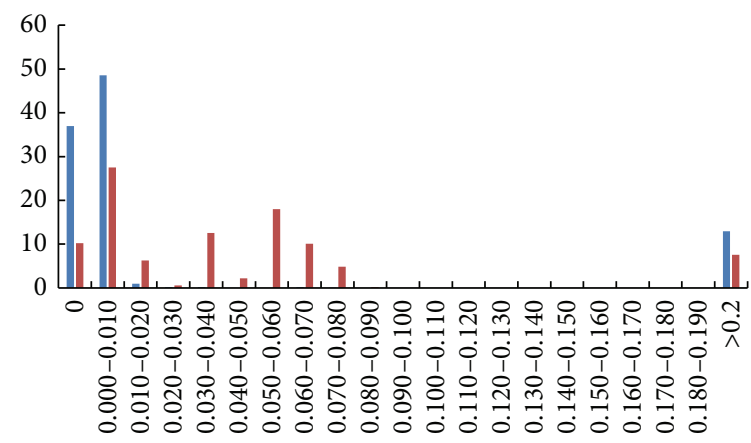

- Intraspecies

- Interspecies

(c)

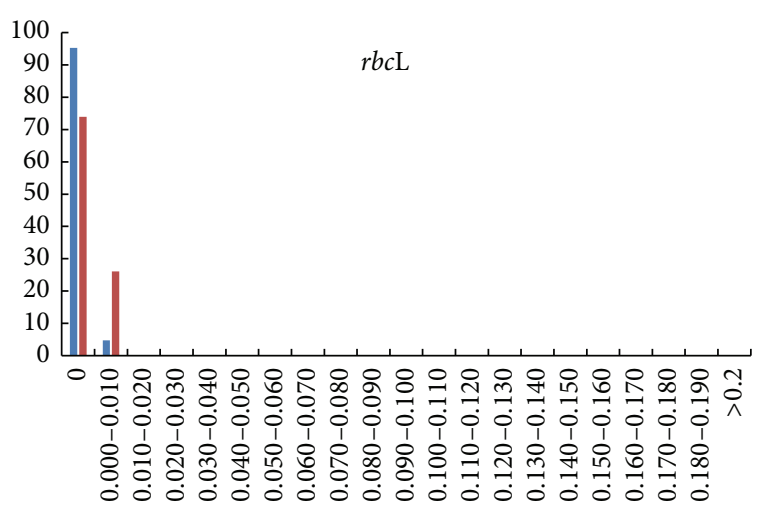

- Intraspecies

- Interspecies

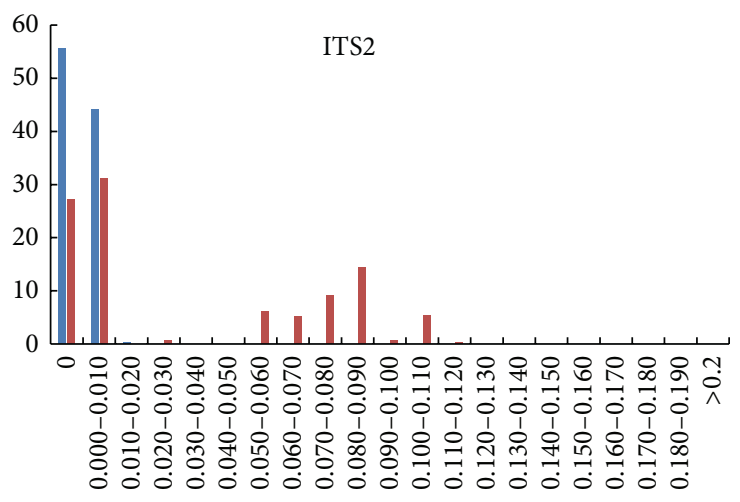

- Intraspecies

- Interspecies

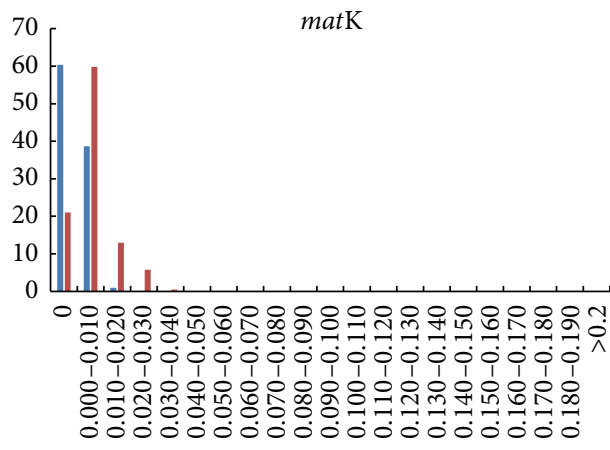

- Intraspecies

- Interspecies

(d)

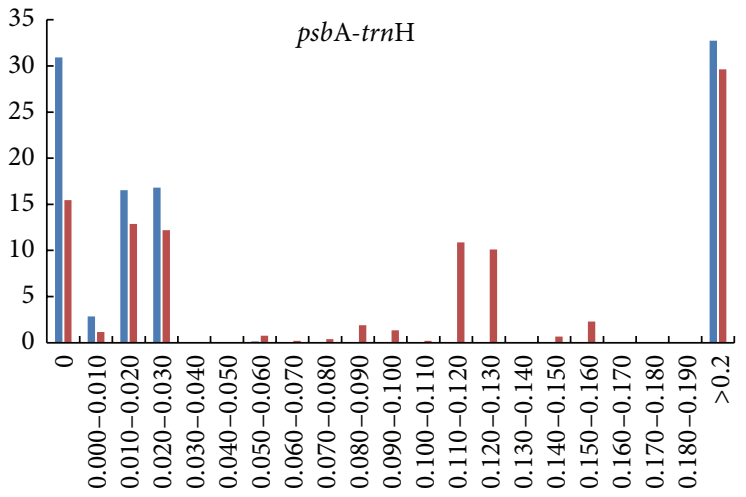

- Intraspecies

- Interspecies

(f)

Figure 1: Barcoding gap for six barcodes.

Astragali. Six indicators, including average genetic distance, BLAST1 and the nearest distance method for identification efficiency, inter- and intraspecific variation, and gap rate were tested to evaluate six DNA barcodes using bioinformatics software and the Perl language algorithm. The ITS sequence was the optimal barcode for identifying Radix Astragali and its adulterants. This method provides a novel means for accurate identification of Radix Astragali and its adulterants and improves the utilization of DNA barcoding in identifying medicinal plant species. 


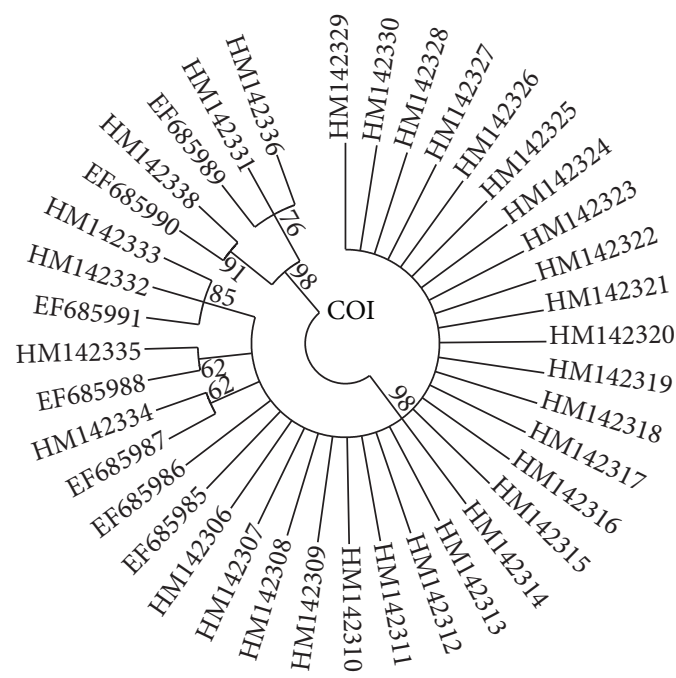

(a)

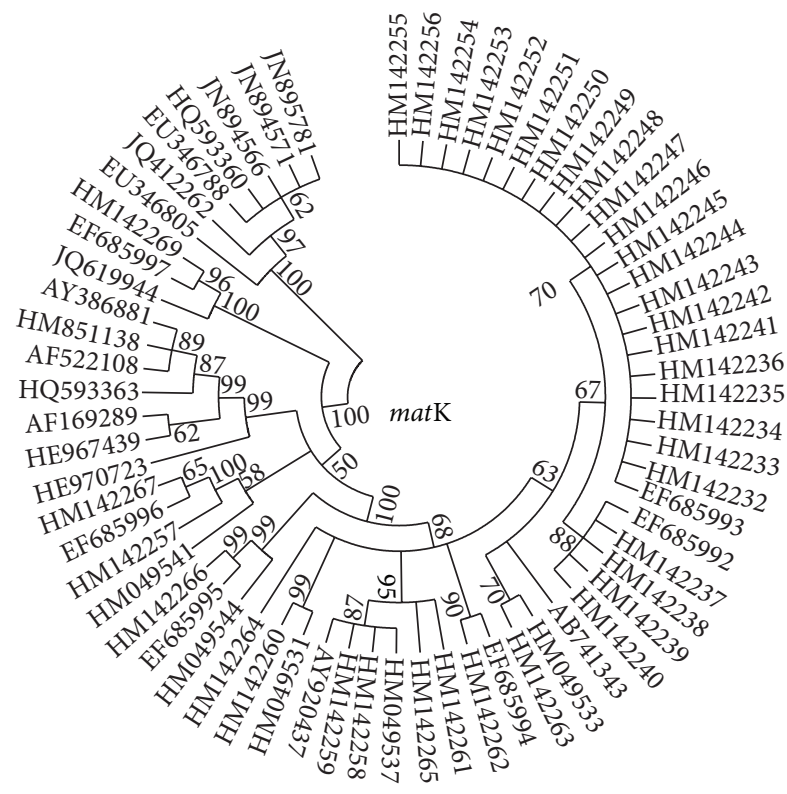

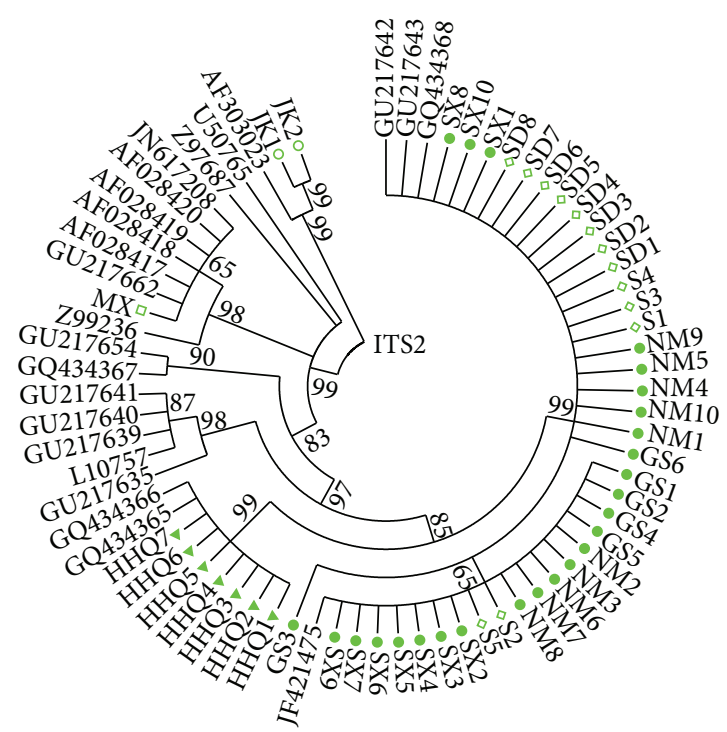

(b)

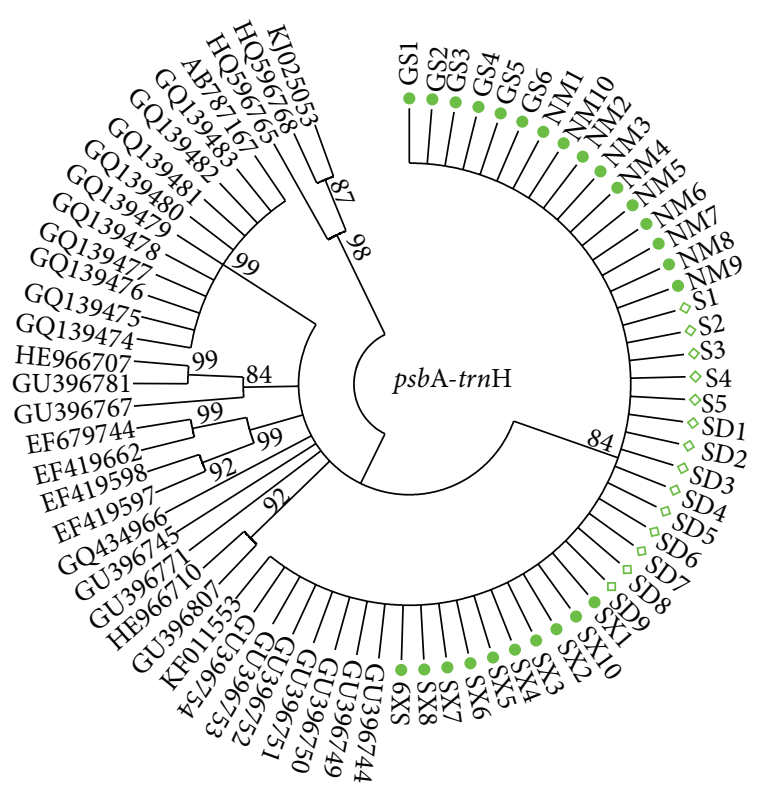

(d)

(c)

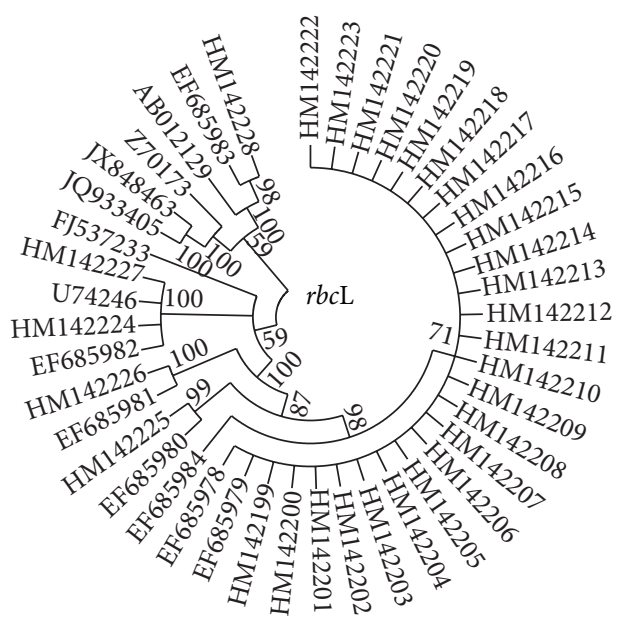

(e)

Figure 2: Continued. 


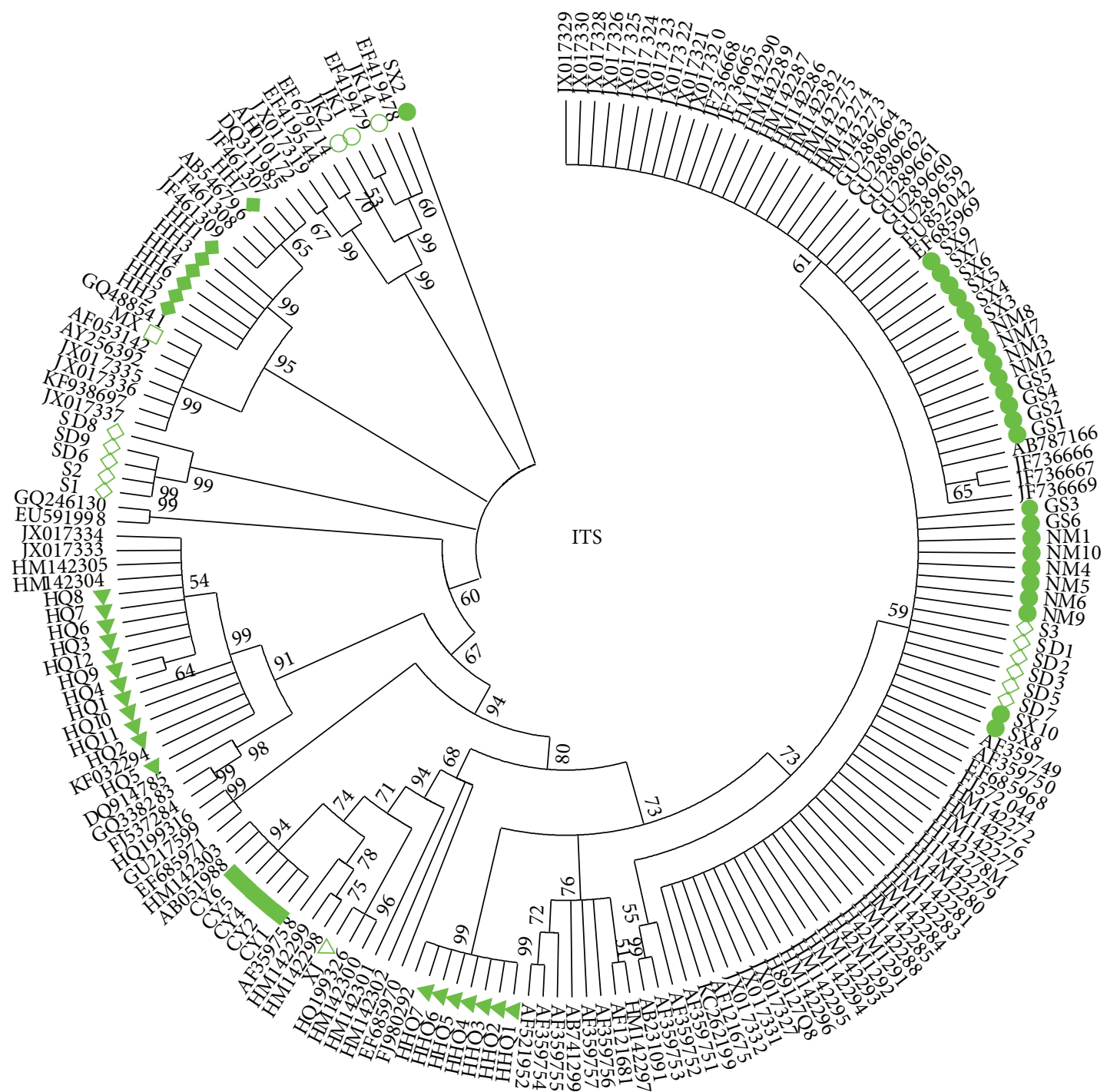

(f)

FiguRE 2: ML tree for six barcodes. ${ }^{*}$ The different color and shape for different species in clusters presented the identification of different barcodes.

TABLE 6: Six indicators assessed for DNA barcoding.

\begin{tabular}{|c|c|c|c|c|c|c|c|}
\hline \multirow{3}{*}{ DNA barcodes } & \multicolumn{7}{|c|}{ Parameters } \\
\hline & \multirow{2}{*}{$\begin{array}{l}\text { Average genetic } \\
\text { distance }\end{array}$} & \multicolumn{2}{|c|}{ Identification efficiency } & \multirow{2}{*}{ Gap rate } & \multirow{2}{*}{$\begin{array}{c}\text { Inter- to } \\
\text { intraspecific } \\
\text { variation }\end{array}$} & \multirow{2}{*}{ Barcoding gap } & \multirow{2}{*}{ Total score } \\
\hline & & BLAST1 & $\begin{array}{c}\text { Nearest } \\
\text { distances }\end{array}$ & & & & \\
\hline ITS2 & 8 & 12 & 8 & 8 & 8 & 4 & 48 \\
\hline ITS & 6 & 28 & 22 & 0 & 0 & 6 & 62 \\
\hline$p s b \mathrm{~A}-t r n \mathrm{H}$ & 6 & 26 & 18 & 0 & 2 & 2 & 54 \\
\hline$r b c \mathrm{~L}$ & 4 & 12 & 14 & 4 & 6 & 8 & 48 \\
\hline mat K & 4 & 14 & 24 & 4 & 4 & 2 & 52 \\
\hline $\mathrm{COI}$ & 2 & 6 & 10 & 6 & 0 & 6 & 30 \\
\hline
\end{tabular}

${ }^{*}$ The total score of six parameters was set by 10,30, 30, 10, 10, and 10 in order. Identification efficiency based on two methods was set by 30 score because of its importance for identification. 


\section{Conflict of Interests}

The authors declare that there is no conflict of interests regarding the publication of this paper.

\section{Acknowledgments}

Thanks are due to the National Natural Science Foundation of China (nos. 81274013, 8130069, and 81473315) and the National Science and Technology Major Projects for "Major New Drugs Innovation and Development" (no. 2011BAI07B01).

\section{References}

[1] Y. Kuo, W. Tsai, S. Loke, T. Wu, and W. Chiou, "Astragalus membranaceus flavonoids (AMF) ameliorate chronic fatigue syndrome induced by food intake restriction plus forced swimming," Journal of Ethnopharmacology, vol. 122, no. 1, pp. 28-34, 2009.

[2] W. C. S. Cho and K. N. Leung, "In vitro and in vivo immunomodulating and immunorestorative effects of Astragalus membranaceus," Journal of Ethnopharmacology, vol. 113, no. 1, pp. 132-141, 2007.

[3] T. T. X. Dong, X. Q. Ma, C. Clarke et al., "Phylogeny of Astragalus in China: molecular evidence $\mathrm{f}$ rom the DNA sequences of 5S rRNA spacer, ITS, and 18S rRNA," Journal of Agricultural and Food Chemistry, vol. 51, no. 23, pp. 6709-6714, 2003.

[4] X. Ma, P. Tu, Y. Chen, T. Zhang, Y. Wei, and Y. Ito, "Preparative isolation and purification of two isoflavones from Astragalus membranaceus Bge. var. mongholicus (Bge.) Hsiao by highspeed counter-current chromatography," Journal of Chromatography A, vol. 992, no. 1-2, pp. 193-197, 2003.

[5] X. Ma, P. Tu, Y. Chen, T. Zhang, Y. Wei, and Y. Ito, "Preparative isolation and purification of isoflavan and pterocarpan glycosides from Astragalus membranaceus Bge. var. mongholicus (Bge.) Hsiao by high-speed counter-current chromatography," Journal of Chromatography A, vol. 1023, no. 2, pp. 311-315, 2004.

[6] P. Y. Yip and H. S. Kwan, "Molecular identification of Astragalus membranaceus at the species and locality levels," Journal of Ethnopharmacology, vol. 106, no. 2, pp. 222-229, 2006.

[7] Y. Z. Zhao, "Investigation the source and distribution of Radix Astragli," Chinese Traditional and Herbal Drugs, vol. 35, no. 10, pp. 1189-1190, 2004.

[8] Y. H. Zhang, L. M. Zhang, X. B. Liu et al., "Study on morphological and microscopic identification for different producing areas of Radix Astragali," Journal of Chinese Medicinal Materials, vol. 36, no. 10, pp. 1602-1604, 2013.

[9] L. Wei and F. T. Zeng, "Using thin-layer chromatography and ultra-violet spectroscopy to identify Radix Astragali and its adulterants," Journal of Chinese Medicinal Materials, vol. 16, no. 12, pp. 14-17, 1993.

[10] G. Li, H. Zhao, Y. Liu et al., "Study on Chinese herb astragalus membranceus by FTIR fingerprint," Spectroscopy and Spectral Analysis, vol. 30, no. 6, pp. 1493-1497, 2010.

[11] X. Q. Ma, Q. Shi, J. A. Duan, T. T. X. Dong, and K. W. K. Tsim, "Chemical analysis of Radix Astragali (Huangqi) in China: a comparison with its adulterants and seasonal variations," Journal of Agricultural and Food Chemistry, vol. 50, no. 17, pp. 4861-4866, 2002.
[12] H. J. Na, J. Y. Um, S. C. Kim et al., "Molecular discrimination of medicinal Astragali radix by RAPD analysis," Immunopharmacology and Immunotoxicology, vol. 26, no. 2, pp. 265-272, 2004.

[13] L. X. Duan, T. L. Chen, M. Li et al., "Use of the metabolomics approach to characterize chinese medicinal material Huangqi," Molecular Plant, vol. 5, no. 2, pp. 376-386, 2012.

[14] P. D. N. Hebert, A. Cywinska, S. L. Ball, and J. R. DeWaard, "Biological identifications through DNA barcodes," Proceedings of the Royal Society B: Biological Sciences, vol. 270, no. 1512, pp. 313-321, 2003.

[15] P. D. N. Hebert, E. H. Penton, J. M. Burns, D. H. Janzen, and W. Hallwachs, "Ten species in one: DNA barcoding reveals cryptic species in the neotropical skipper butterfly Astraptes fulgerator," Proceedings of the National Academy of Sciences of the United States of America, vol. 101, no. 41, pp. 14812-14817, 2004.

[16] S. H. Zheng, X. Jiang, L. B. Wu, Z. H. Wang, and L. F. Huang, "Chemical and genetic discrimination of cistanches herba based on UPLC-QTOF/MS and DNA barcoding," PLoS ONE, vol. 9, no. 5, Article ID e98061, 2014.

[17] L. F. Huang, S. H. Zheng, L. B. Wu, X. Jiang, and S. L. Chen, "Ecotypes of Cistanche deserticolabased on chemical component and molecular traits," Scientia Sinica Vitae, vol. 44, no. 3, pp. 318-328, 2014.

[18] X. Q. Ma, J. A. Duan, D. Y. Zhu, T. T. X. Dong, and K. W. K. Tsim, "Species identification of Radix Astragali (Huangqi) by DNA sequence of its 5S-rRNA spacer domain," Phytochemistry, vol. 54, no. 4, pp. 363-368, 2000.

[19] G. Chen, X. L. Wang, W. S. Wong, X. D. Liu, B. Xia, and N. Li, "Application of 3/ Untranslated Region (UTR) sequence-based amplified polymorphism analysis in the rapid authentication of Radix astragali," Journal of Agricultural and Food Chemistry, vol. 53, no. 22, pp. 8551-8556, 2005.

[20] J. Liu, H.-B. Chen, B.-L. Gou, Z.-Z. Zhao, Z.-T. Liang, and T. Yi, "Study of the relationship between genetics and geography in determining the quality of Astragali Radix," Biological and Pharmaceutical Bulletin, vol. 34, no. 9, pp. 1404-1412, 2011.

[21] Z. H. Cui, Y. Li, Q. J. Yuan, L. Zhou, and M. Li, "Molecular identification of Astragali Radix and its adulterants by ITS sequences," China Journal of Chinese Materia Medica, vol. 37, no. 24, pp. 3773-3776, 2012.

[22] T. Gao, H. Yao, X. Y. Ma, Y. J. Zhu, and J. Y. Song, "Identification of Astragalus plants in China using the region ITS2," World Science and Technology/Modernization of Traditional Chinese Medicine and Materia Medica, vol. 12, no. 2, pp. 222-227, 2010.

[23] H.-Y. Guo, W.-W. Wang, N. Yang et al., "DNA barcoding provides distinction between Radix Astragali and its adulterants," Science China Life Sciences, vol. 53, no. 8, pp. 992-999, 2010.

[24] CBOL Plant Working Group, "A DNA barcode for land plants," Proceedings of the National Academy of Sciences of United States of America, vol. 106, no. 31, pp. 12794-12797, 2009.

[25] S. L. Chen, H. Yao, J. P. Han et al., "Validation of the ITS2 region as a novel DNA barcode for identifying medicinal plant species," PLoS ONE, vol. 5, no. 1, Article ID e8613, 2010.

[26] W. J. Kress, K. J. Wurdack, E. A. Zimmer, L. A. Weigt, and D. H. Janzen, "Use of DNA barcodes to identify flowering plants," Proceedings of the National Academy of Sciences of the United States of America, vol. 102, no. 23, pp. 8369-8374, 2005.

[27] A. Keller, T. Schleicher, J. Schultz, T. Müller, T. Dandekar, and M. Wolf, "5.8S-28S rRNA interaction and HMM-based ITS2 annotation," Gene, vol. 430, no. 1-2, pp. 50-57, 2009. 
[28] K. Tamura, G. Stecher, D. Peterson, A. Filipski, and S. Kumar, "MEGA6: molecular evoluationaay genetics analysis version 6.0," Molecular Biology and Evolution, vol. 30, no. 12, pp. 27252729, 2013.

[29] C. P. Meyer and G. Paulay, "DNA barcoding: error rates based on comprehensive sampling," PLoS Biology, vol. 3, no. 12, article e422, 2005.

[30] H. A. Ross, S. Murugan, and W. L. S. Li, "Testing the reliability of genetic methods of species identification via simulation," Systematic Biology, vol. 57, no. 2, pp. 216-230, 2008.

[31] D. A. Morrison, "Increasing the efficiency of searches for the maximum likelihood tree in a phylogenetic analysis of up to 150 nucleotide sequences," Systematic Biology, vol. 56, no. 6, pp. 988-1010, 2007.

[32] Y. P. Zhang, M. K. Nie, S. Y. Shi et al., "Integration of magnetic solid phase fishing and off-line two-dimensional highperformance liquid chromatographydiode array detectormass spectrometry for screening and identification of human serum albumin binders from Radix Astragali," Food Chemistry, vol. 146, no. 1, pp. 56-64, 2014.

[33] X. H. Liu, L. G. Zhao, J. Liang et al., "Component analysis and structure identification of active substances for anti-gastric ulcer effects in Radix Astragali by liquid chromatography and tandem mass spectrometry," Journal of Chromatography B, vol. 960, no. 1, pp. 43-51, 2014.

[34] C. Chu, H.-X. Cai, M.-T. Ren et al., "Characterization of novel astragaloside malonates from Radix Astragali by HPLC with ESI quadrupole TOF MS," Journal of Separation Science, vol. 33, no. 4-5, pp. 570-581, 2010.

[35] J. Fu, L. F. Huang, H. T. Zhang, S. H. Yang, and S. L. Chen, "Structural features of a polysaccharide from Astragalus membranaceus (Fisch.) Bge. var. mongholicus (Bge.) Hsiao," Journal of Asian Natural Products Research, vol. 15, no. 6, pp. 687-692, 2013.

[36] X. Huang, Y. Liu, F. Song, Z. Liu, and S. Liu, "Studies on principal components and antioxidant activity of different Radix Astragali samples using high-performance liquid chromatography/electrospray ionization multiple-stage tandem mass spectrometry," Talanta, vol. 78, no. 3, pp. 1090-1101, 2009.

[37] A. Nalbantsoy, T. Nesil, Ö. Yilmaz-Dilsiz, G. Aksu, S. Khan, and E. Bedir, "Evaluation of the immunomodulatory properties in mice and in vitro anti-inflammatory activity of cycloartane type saponins from Astragalus species," Journal of Ethnopharmacology, vol. 139, no. 2, pp. 574-581, 2012.

[38] W. L. Xiao, T. J. Motley, U. J. Unachukwu et al., "Chemical and genetic assessment of variability in commercial Radix Astragali (Astragalus spp.) by ion trap LC-MS and nuclear ribosomal DNA barcoding sequence analyses," Journal of Agricultural and Food Chemistry, vol. 59, no. 5, pp. 1548-1556, 2011. 


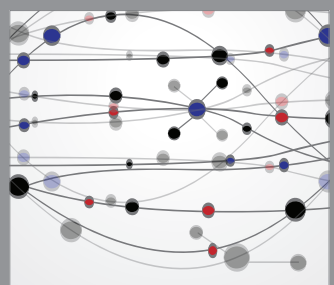

The Scientific World Journal
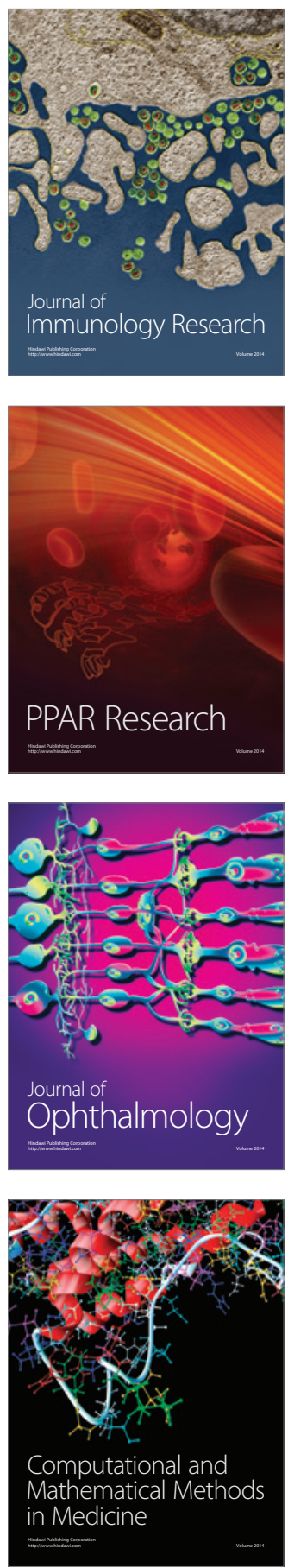

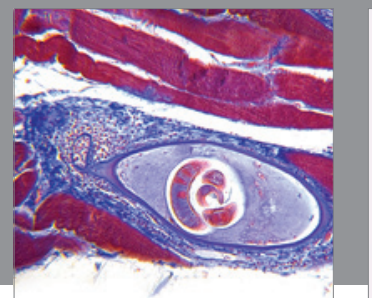

Gastroenterology

Research and Practice
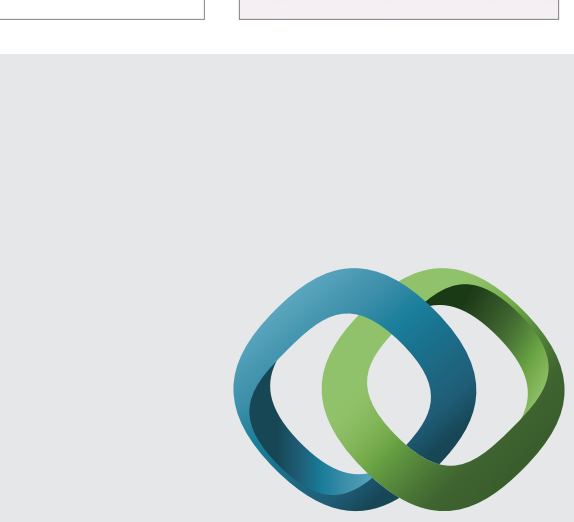

\section{Hindawi}

Submit your manuscripts at

http://www.hindawi.com
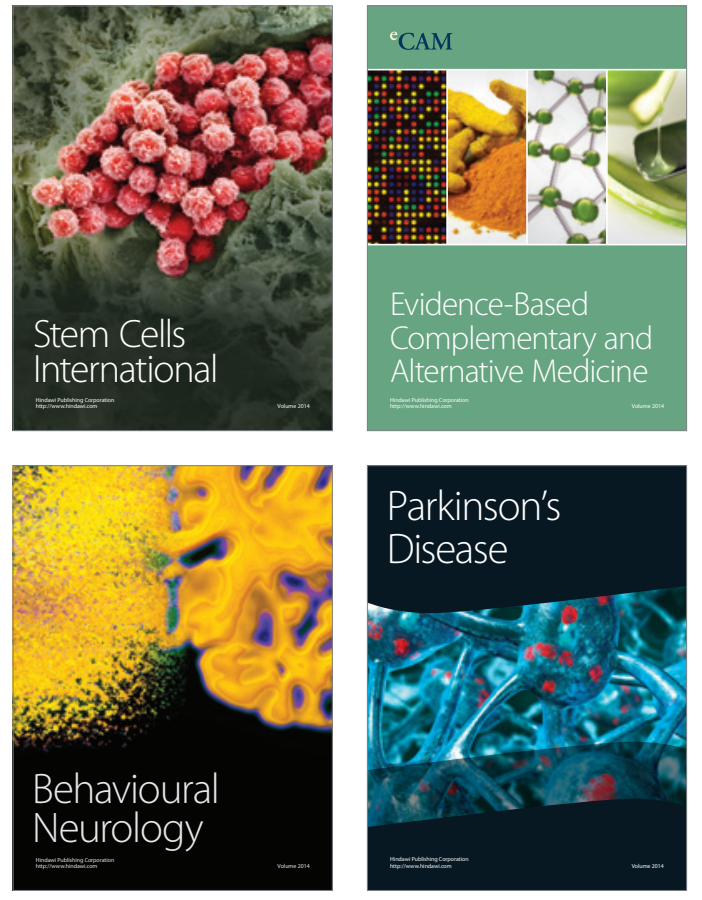
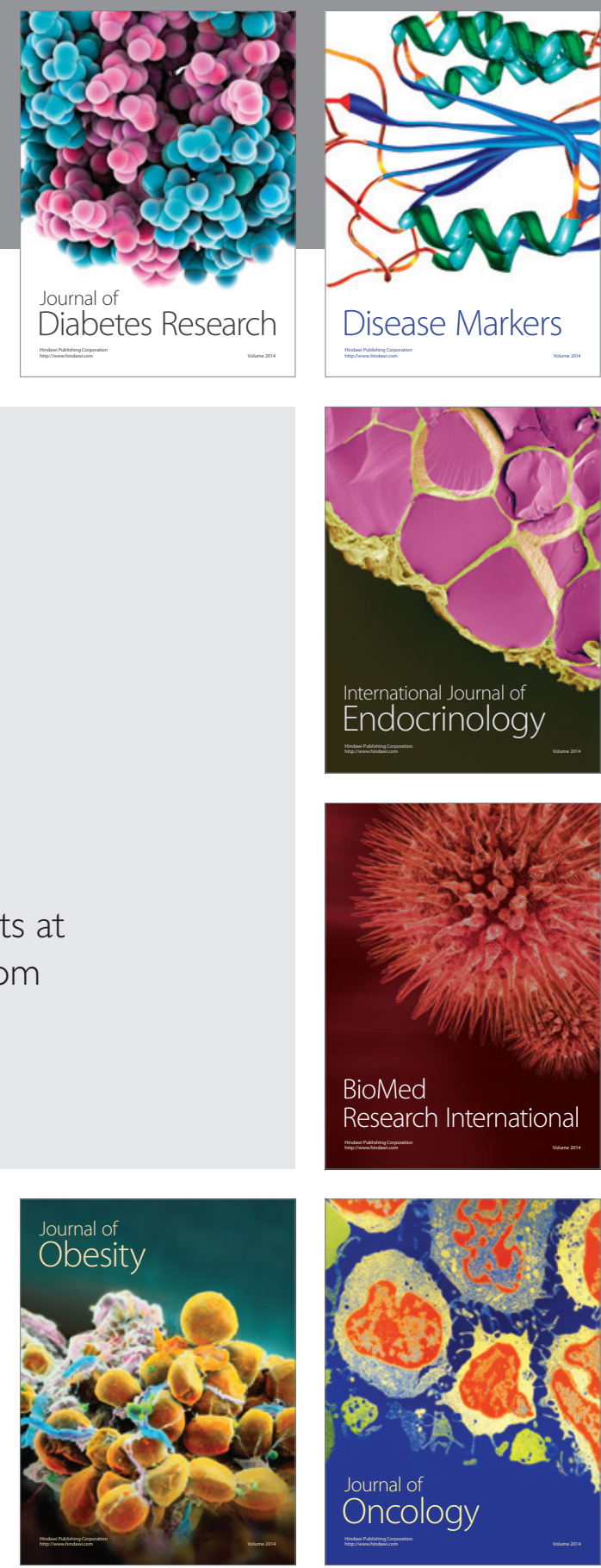

Disease Markers
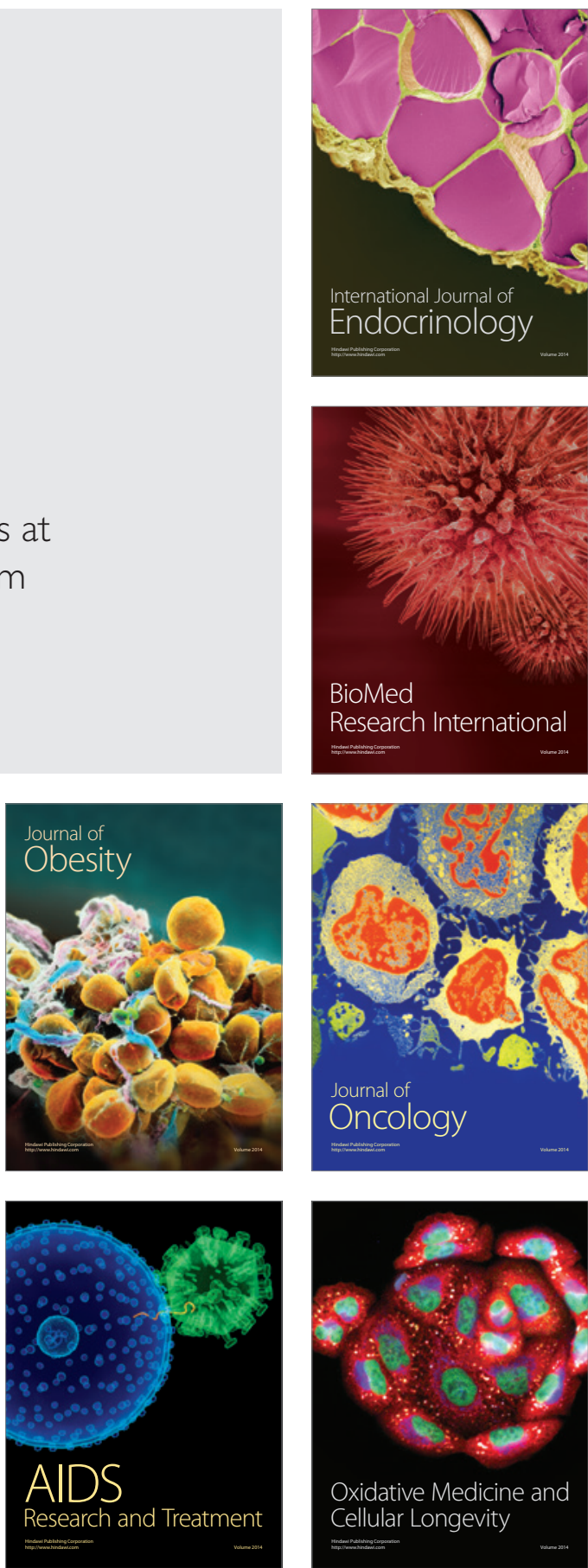